\title{
Molecular adsorbent recirculating system therapy in a rare case of fulminant hepatitis
}

\author{
Vincenzo Morabito $^{1 *}$, Giancarlo Ferretti ${ }^{2}$, Francesco Pugliese ${ }^{3}$, Simone Novelli $^{4}$, Massimo Rossi $^{1}$, \\ Gilnardo Novelli ${ }^{1}$ \\ ${ }^{1}$ Department “P. Stefanini” General Surgery and Organs Transplant, Sapienza University of Rome, Rome, Italy \\ ${ }^{2}$ Department of Infectous Disease, Sapienza University of Rome, Rome, Italy \\ ${ }^{3}$ Department of Aenesthetic Science and Critical Care Medicine, Sapienza University of Rome, Rome, Italy \\ ${ }^{4}$ Department of Clinical Engineering, Sapienza University of Rome, Rome, Italy \\ Email: ${ }^{*}$ vinmorabito@aol.com
}

Received 11 February 2012; revised 18 March 2012; accepted 29 March 2012

\begin{abstract}
Background: Acute hepatitis $C$ virus infection leading to fulminant hepatitis is very rare whereas Hepatitis $\mathrm{C}$ virus (HCV) infection is one of the main causes of chronic liver disease worldwide. The repertoire of substances that accumulate in the blood in fulminant hepatic failure cause neurological abnormalities, aggravate injury to the liver and other organs, suppress the ability of residual hepatocytes to perform organspecific functions (sick cell syndrome), and inhibit the hepatic regenerative response especially in fulminant hepatitis Virus $\mathbf{C}$ which has subacute clinical evolution and takes time to manifest. Liver support technology is evolving as different techniques become available that assist the remaining functional cell mass by providing specific liver functions. Case Presentation: We report a case of Fulminant $C$ virus Hepatitis, successfully treated with albumin dialysis Molecular Adsorbent Recirculating System (MARS). At time of admittance the patient presented: Model End-stage Liver Disease (MELD)-36; Child Turcotte Pugh (CTP) -C(13); Sequential Organ Failure Assestment (SOFA) -12, Glasgow Coma Score (GCS)-11. The patient underwent six sessions of MARS in Intensive Care Unit (ICU) in association with standard medical therapy (SMT). The patient survived and was discharged from the hospital in good condition after 40 days without liver transplantation (LT).
\end{abstract}

Keywords: Acute Liver Failure; Hepatic Devices; Cytokines; Molecular Adsorbent Recirculating System

\section{INTRODUCTION}

Acute hepatitis $\mathrm{C}$ virus infection leading to fulminant hepatitis is very rare whereas Hepatitis C virus (HCV)

\footnotetext{
"Corresponding author.
}

infection is one of the main causes of chronic liver disease worldwide [1]. It is estimated that $3 \%$ of the world population is chronically infected with $\mathrm{HCV}[1,2]$. In Europe the epidemic of $\mathrm{HCV}$ infection is continuously evolving and epidemiological parameters (prevalence, incidence, disease transmission patterns and genotype distribution) have changed substantially during the last 5 years [3-7].

The incidence of acute HCV infections is decreasing in developed countries, but could be increasing in developing countries because of unsafe medical practices. In Europe, HCV infection is responsible for about $10 \%$ $20 \%$ of cases of acute hepatitis which varies from country to country [8]. The incidence of acute HCV infection is probably underestimated because it may exclude asymptomatic infections. Acute hepatitis can occur $2-12$ weeks after exposure and it can be severe and prolonged but is almost never fulminant.

The repertoire of substances that accumulate in the blood in fulminant hepatic failure cause neurological abnormalities, aggravate injury to the liver and other organs, suppress the ability of residual hepatocytes to perform organ-specific functions (sick cell syndrome), and inhibit the hepatic regenerative response especially in fulminant hepatitis Virus $\mathrm{C}$ which has subacute clinical evolution and takes time to manifest. In recent years, the mortality rate associated with acute liver failure has declined from $100 \%$ to $60 \%-70 \%$.

However, despite this decline in the mortality rate, cases can rapidly progress to coma and death. In most cases, the most useful treatment is liver transplantation (LT), but, unfortunately, this procedure is available in only $\sim 50 \%$ of cases [9]. In fact survival without transplant is poor in hyperacute and acute patients with advanced encephalopathy with risk of substantial cerebral edema and intracranial hypertension. In patients with subacute disease even the presence of modest hepatic encephalopathy suggests critically impaired liver func- 
tion that, although infrequently associated with intracranial hypertension, is a sign of poor outlook [10].

The management of precipitating events in liver failure requires time to allow enough liver cells to regain regenerative function or for an organ to become available for transplant. Hence, time remains the crucial factor in successfully managing liver disease. Liver support technology is evolving as different techniques become available that assist the remaining functional cell mass by providing specific liver functions [11]. The major objective of liver support is to buy time. The molecular adsorbent recirculating system (MARS) [12], a type of albumin dialysis, is used as a bridging therapy either to optimize the clinical status for LTx or to provide a resolution without LTx. In acute cases it could therefore be useful to use this extracorporeal support to avoid degeneration leading to fulminant hepatitis.

\section{CASE REPORT}

\subsection{Patient}

In March 2011, a 42 year-old Caucasian female with signs of massive jaundice, severe coagulophathy and
Encephalopathy Grade (EG) III was hospitalized in Intensive Care Unit (ICU), three days after the first symptoms of the disease. She had never consumed alcohol and she had not undergone surgery. The patient led a life of substantial wealth and was a blood donor, she had made the last donation 60 days before hospitalization with negative viral markers. About twenty days before, she had had a temperature $\left(39.5^{\circ} \mathrm{C}\right)$ associated with vomiting and diarrhea alternating with remission and flare. At time of admittance, the patient presented: Model End-stage Liver Disease (MELD)-37; Child Turcotte Pugh (CTP)C(13); Sequential Organ Failure Assestment (SOFA)-12. Neurological status was monitored by Glasgow Coma Score (GCS) and Encephalopathy Grade(EG). Patient data are summarized in Table 1.

Monitoring of intracranial pressure (ICP) was carried out by Transcranial Doppler (TCD). Doppler US criteria were: for TCD, we placed the probe of $2 \mathrm{MHz}$ on the temporal aspect of the head, chephalad to the zygomatic arch, and immediately anterior and slightly superior to the trogus of the ear conch; in this way, we were able to penetrate the skull and accurately measure blood flow velocities in the circle of Willis, with an insonation depth

Table 1. Laboratory findings before MARS treatment.

\begin{tabular}{|c|c|c|c|}
\hline \multicolumn{4}{|l|}{ Biochemical Parameters } \\
\hline Bilurubine Tot. (mg/dl) & 23 & Bilirubine Dir. (mg/dl) & 14.6 \\
\hline Urea $(\mathrm{mg} / \mathrm{dl})$ & 40 & Creatinine $(\mathrm{mg} / \mathrm{dl})$ & 1.5 \\
\hline Albumine (mg/dl) & 2.8 & Glucose (mg/dl) & 85 \\
\hline $\operatorname{AST}(\mathrm{mg} / \mathrm{dl})$ & 3980 & $\operatorname{ALT}(\mathrm{mg} / \mathrm{dl})$ & 3230 \\
\hline Colinesterasis (mg/dl) & 3400 & Ammonium (mg/dl) & 225 \\
\hline Serum Sodium (mg/dl) & 132 & Lactates $(\mathrm{mmol} / \mathrm{L})$ & 6.1 \\
\hline INR & 3.5 & & \\
\hline \multicolumn{4}{|l|}{ Cytokines (pg/ml) } \\
\hline IL-6 & 81.6 & TNF- $\alpha$ & 57.1 \\
\hline IL-1 & 37.2 & IL-10 & 18.3 \\
\hline \multicolumn{4}{|l|}{ Hemodinamyc Targets } \\
\hline $\mathrm{mAP}(\mathrm{mmHg})$ & 54 & $\mathrm{CI}\left(1 / \mathrm{min} / \mathrm{m}^{2}\right)$ & 6.5 \\
\hline SVRI (dynes $/ \mathrm{cm}^{5} / \mathrm{m}^{2}$ ) & 770 & PVRI (dynes $/ \mathrm{cm}^{5} / \mathrm{m}^{2}$ ) & 300 \\
\hline CVP (mmHg) & 13 & $\mathrm{PH}$ & 7.51 \\
\hline Sat $\mathrm{O}_{2}(\%)$ & 79 & $\mathrm{FiO}_{2}(\%)$ & 100 \\
\hline $\mathrm{DO}_{2}\left(\mathrm{~mL} / \mathrm{min} \cdot \mathrm{m}^{-2}\right)$ & 698 & $\mathrm{VO}_{2}\left(\mathrm{~mL} / \mathrm{min} \cdot \mathrm{m}^{-2}\right)$ & 187 \\
\hline \multicolumn{4}{|l|}{ Predictiva Criteria } \\
\hline MELD & 36 & SOFA & 12 \\
\hline CTP & $\mathrm{C}(13)$ & GCS & 11 \\
\hline \multicolumn{4}{|c|}{ Auto immune antibody values } \\
\hline ANA & neg & ASMA & neg \\
\hline AMA & neg & & \\
\hline
\end{tabular}

Note: AST: Serum Aspartate amino-Transferase; HCV : Hepatitis C virus; HBs-Ag: Hepatitis B virus surface antigen; HBs-Ab: Hepatitis B virus surface antibody; HAV: Hepatitis A virus; CMV: Cytomegalovirus; ALT: Serum Alanine aminoTransferase ; INR: International Normal Ratio; IL: Interlukine; TNF: Tumor Necrosis Factor; mAP: mean Arterial Pressure; CI: Cardiac Index; SVRI: Systemic Vascular Resistance Index, PVRI: Pulmonary Resistence Vascular Index; CVP: Cental Pressure Venous; MELD: Model End-stage Liver Desease; SOFA: Sequential Organ Failure Assestment; CTP: Child Turcotte Pugh; GCS: Glasgow Coma Score; ANA: antinuclear antibody; ASMA: anti smooth muscle antibody; AMA: anti mitochondrial antibody. 
of $50 \mathrm{~mm}$ (range: $30-60 \mathrm{~mm}$ ). A Doppler angle of $50^{\circ}$ $60^{\circ}$ was used.

Hemodynamic instability was monitored through values of mean arterial pressure (mAP), heart rate (HR), cardiac index (CI), systemic vascular resistance index (SVRI) and pulmonary vascular resistance index(PVRI). The patient was monitored with a radial artery cannula for arterial pressure and periodic blood sampling for gas analysis cannulated subclavian vein, and a Swan Ganz catheter was inserted to evaluate continuous hemodynamic changes and Central Venous Pressure (PVC) with Monitor Vigilance (Edwards Lifesciences, Irvine, Calif).

The patient received standard medical therapy such as appropriate antibiotics, diuretics, parenteral mannitol (18\%), fresh frozen plasma and platelets. An electroencephalography revealed generalized slowing of baseline activity and generalized periodic delta frequency with spikes of slow waves. This was considered a sign of acute liver failure.

Her abdominal ultrasonography revealed the presence of hepatomegaly along with dilatation of hepatic veins and inferior vena cava. The patient fulfilled the diagnostic criteria of Acute Liver Failure as initially published by Trey and Davidson [13] as well as those recently defined by the American Association for the Study of Liver Diseases (hepatic encephalopathy, acute-onset increase of INR $>1.5$, and absence of signs of chronic liver disease in clinical and ultrasound examination).

Clinical status: UNOS classification Status 1 and therefore emergency LT was requested. Because of the rapid hepatic decompensation and the low probability of an available cadaver donor, we conducted a treatment protocol with MARS.

\subsection{Diagnosis}

Extensive serologic investigations including assays for hepatitis $\mathrm{A}, \mathrm{B}$ and $\mathrm{C}$ related as well as repeated blood cultures were positive for Hepatitis C Virus (Table 2). The presence of the virus is tested for using molecular nucleic acid testing methods such as polymerase chain reaction (PCR), transcription mediated amplification (TMA). None of the serum samples had detectable levels of hepatitis B surface antigen, IgM antibodies against hepatitis A or hepatitis B core antigens, or antibodies against cytomegalovirus, Epstein-Barr virus, or the human immunodeficiency virus. To exclude the possibility of coinfection with HBV and hepatitis G virus (HGV), all serum samples were tested for the presence of HBV DNA and HGV RNA by the polymerase chain reaction (PCR), and all were negative.

\subsection{Albumin Dialisys MARS Protocol}

The MARS ${ }^{\circledR}$ (Gambro, Stockholm, Sweden) uses albu- min as a molecular adsorbent to remove toxins bound to albumin. The blood circuit is driven by the blood roller pump of the dialysis machine (Hospal Integra; Gambro, Zaventem, Belgium).

The patient underwent 6 sessions in continuous with kit change every 8 hours. MARS can be applied with good tolerability for long sessions.

Vascular access was obtained by insertion of a doublelumen dialysis catheter (Arrow International, Inc, Reading, PA, USA) into the right internal jugular vein.

For anticoagulation, a bolus of 2500 units of unfractionated heparin was injected into the system during priming; $120 \pm 25 \mathrm{~mL}$ of saline solution was performed every 60 minutes to prevent dialyzer clotting. Application of extracorporeal flows were as follows: blood flow rate $175 \pm 15 \mathrm{~mL} / \mathrm{min}$, albumin circuit flow rate $190 \pm 05$ $\mathrm{mL} / \mathrm{min}$ and bicarbonate dialysate flow rate $500 \mathrm{~mL} / \mathrm{min}$.

During treatment the concentration of albumin and albumin bound-toxins changes both in the circuit and in the patient from hour to hour. The gradient of albumin concentration in patient and albumin level in circuit must remain constant and should be $\Delta=1$. Therefore, if delta between patient albumin and circuit albumin is $\Delta<1,50$ - $100 \mathrm{ml}$ human albumin (20\%) must be administered to patient and $25-50 \mathrm{ml}$ human albumin $(20 \%)$ must be used in circuit.

\subsection{Cytokine Assays}

Serum values with relation to inflammation (interleukine $1 \beta$, interleukine 6, interleukine10, Tumor Necrosis Factor alpha) were observed. Blood samples were drawn at baseline, at the end of single treatment. Samples were centrifuged after 30 minutes and serum aliquots were stored frozen at $-70^{\circ} \mathrm{C}$ for later assay of cytokines. IL6 and IL1 $\beta$ were analyzed by a chemoluminescent assay (Immulite 2000, DPC Biermann GmbH, Bad Nauheim, Germany). ELISA was used to determine IL10,

Table 2. Results of viral laboratory tests at admission.

\begin{tabular}{ll}
\hline HCV-RNA (gen/mil) & 8.990 .000 \\
\hline HCV genotype & $2 \mathrm{a}$ \\
$\mathrm{HCV} \mathrm{Ab}$ & negative \\
$\mathrm{HBsAb}$ & negative \\
$\mathrm{HBsAg}$ & negative \\
IgM anti HBc & negative \\
$\mathrm{HAV}$ & negative \\
IgM anti-HAV & negative \\
$\mathrm{CMV}$ & negative \\
IgM anti-CMV & negative \\
HIV & negative \\
\hline
\end{tabular}

Note: HCV: hepatitis virus C; HBsAg: hepatitis B sirus surface antigen; HBsAb: hepatitis B sirus surface antibody; HAV: hepatitis virus A; CMV: cytomegalovirus. 
TNF $\alpha$ (Quantikine ${ }^{2}, \mathrm{R} \& \mathrm{D}$ Systems, Minneapolis, MN, USA).

\section{RESULTS}

There are three theories that describe the MARS mechanism of action. First, using albumin, MARS can cleanse the blood of albumin-bound toxins and the liver can recover, or the patient can stabilize long enough to receive a transplant. Second, the MARS stops the intrahepatic inflammatory process that leads to cell death and multi organ failure; this may lead to improved liver function and patient stabilization. Third, the MARS non only cleanses the blood of toxins, but also improves the albumin capacity, which allows the albumin to carry more toxins to be removed. Acute inflammatory process worsens the neurological and hemodynamic condition.
Detoxification procedures to eliminate ALF toxins that produce encephalopathy and hemodynamic instability seem mandatory as lifesaving treatments to bridge the time that is necessary to prepare successful transplantation. After 48 hours in continuous treatment with albumin dialysis, we obtained a reduction of some cytokines (Table 2) and an improvement of neurological status and

Table 3. Cytokines changes during MARS treatments.

\begin{tabular}{cccc}
\hline Cytokines & II treatment & IV treatment & VIII treatment \\
\hline IL-1 $(\mathrm{pg} / \mathrm{ml})$ & 34.4 & 29.6 & 21.8 \\
IL-6 $(\mathrm{pg} / \mathrm{ml})$ & 66.7 & 40.8 & 27.1 \\
IL-10 $(\mathrm{pg} / \mathrm{ml})$ & 18.1 & 17.7 & 12.2 \\
TNF- $\alpha(\mathrm{pg} / \mathrm{ml})$ & 33.4 & 26.3 & 19.9 \\
\hline
\end{tabular}

Note: IL: Interlukine; TNF: Tumor Necrosis Factor.

Table 4. Hemodynamic targets improvement during MARS treatments.

\begin{tabular}{lccc}
\hline & II treatment & IV treatment & VIII treatment \\
\hline $\mathrm{mAP}(\mathrm{mmHg})$ & 65 & 70 & 80 \\
$\mathrm{Cl}\left(\mathrm{l} / \mathrm{min} / \mathrm{m}^{2}\right)$ & 6.7 & 5.3 & 3.9 \\
$\mathrm{SVRI}\left(\right.$ dynes $\left./ \mathrm{cm}^{5} / \mathrm{m}^{2}\right)$ & 890 & 1150 & 1360 \\
$\mathrm{PVRI}\left(\right.$ dynes $\left./ \mathrm{cm}^{5} / \mathrm{m}^{2}\right)$ & 300 & 270 & 190 \\
$\mathrm{CVP}(\mathrm{mmHg})$ & 12 & 9 & 7 \\
$\mathrm{DO}_{2}\left(\mathrm{~mL} / \mathrm{min} \cdot \mathrm{m}^{-2}\right)$ & 624 & 563 & 445 \\
$\mathrm{VO}_{2}\left(\mathrm{~mL} / \mathrm{min} \cdot \mathrm{m}^{-2}\right)$ & 155 & 139 & 129 \\
$\mathrm{PH}$ & 7.44 & 7.44 & 7.42 \\
$\mathrm{Sat}_{2}(\%)$ & 100 & 100 & 50 \\
$\mathrm{FiO}_{2}(\%)$ & 94 & 97 & 98 \\
\hline
\end{tabular}

mAP: mean Arterial pressure; Cl: Cardiac Index; Systemic Vascular Resistance Index, PVRI: Pulmonary resistence Vascular Index.

Table 5. Biochemical and neurological changes during MARS treatments.

\begin{tabular}{lccc}
\hline & II treatment & IV treatment & VIII treatment \\
\hline Bilurubine Tot. (mg/dl) & 16 & 12 & 5.5 \\
Bilirubine Dir. (mg/dl) & 11 & 9.1 & 3.8 \\
Urea (mg/dl) & 27 & 15 & 12 \\
Creatinine (mg/dl) & 0.9 & 0.6 & 0.5 \\
Albumine (mg/dl) & 3.1 & 4.1 & 3.8 \\
Glucose (mg/dl) & 100 & 145 & 125 \\
AST (UI/L) & 1660 & 760 & 450 \\
ALT (UI/L) & 1250 & 550 & 210 \\
Colinesterasis (mg/dl) & 4620 & 6550 & 8900 \\
Arterial Ammonium & 115 & 70 & 25 \\
GCS & 11 & 12 & 14 \\
Serum Sodium (mg/dl) & 140 & 140 & 140 \\
Lactates (mmol/L) & 4.8 & 3.3 & 1.7 \\
INR & 2.1 & 1.6 & 1.3 \\
\hline
\end{tabular}

AST: Serum Aspartate Amino-Transferase; ALT: Serum Alanine Amino-Transferase; GCS: Glasgow Coma Score; INR: International Normal Ratio. 
hemodynamic instability as reported in Table 3 and Table 4 respectively. Biochemical parameter results are reported in Table 5.

\section{DISCUSSIONS}

The role of hepatitis $\mathrm{C}$ virus (HCV) in fulminant hepatitis remains controversial. The detection of serum HCV RNA was the earliest marker for the diagnosis of fulminant hepatitis $\mathrm{C}$. In contrast, anti-HCV was detected only ten days before the patient's discharge.

This suggests that in fulminant hepatitis, because of the extremely rapid course of the disease, there may not always be sufficient time for the development of antibodies. In our patient, fulminant hepatitis $\mathrm{C}$ was characterized by high levels of viremia.

Although the pathogenetic mechanism of virally induced fulminant hepatic failure is not known, the extent of liver damage correlated with the magnitude of viral replication in the absence of detectable antibodies. In contrast, in patients with fulminant hepatitis B, HBV replication is barely detectable or is undetectable, and antibody titers are high.

Acute liver failure (ALF) virus related results in an endogenous accumulation of toxins involved in the impairment of cardiovascular, kidney and cerebral function. Moreover, it has been shown that these toxins damage the liver itself by inducing hepatocellular apoptosis and necrosis, thus creating a vicious cycle of hepatic injury [14].

Circulating inflammation mediators have been connected to the pathophysiology of hemodynamic instability, cerebral edema, and other multiple organ dysfunctions seen in ALF [15]. Inflammatory cytokines are essential for an adequate host defense system. However, excessive production of these cytokines cause many deleterious effects.

We found that increases in Tumor Necrosis Factoralpha (TNF- $\alpha$ ), Interleukine-1 (IL-1) and Interleukine-6 (IL-6) were more marked on admission in patients with fulminant viral hepatitis than in other etiologies such as acetaminophen, Wilson's disease and indeterminate; suggesting that these cytokines are important in the pathogenesis of the clinical features of fulminant hepatitis.

In this study, all measured cytokines were removed, because the molecular weights of the cytokines studied were below the cutoff point of MARS membrane. After $8 \mathrm{hr}$ per six treatments, we obtained an improvement of clinical status.

There was a significant correlation between TNF- $\alpha$ and IL- 6 and maximum coma grade level in this patient. In contrast, serum cytokine levels were not significantly correlated with other markers of disease severity in ALF such as ALT, INR and serum sodium. These findings suggest that serum cytokines might have unique potential for prediction of outcome and could be used in conjunction with other outcome variables (hemodynamic instability, lactates and neurological status) to enhance development of a prediction rule for outcome in ALF.

At the end of treatments the patient presented a MELD 15 and SOFA 6. Monitoring of cerebral function is mandatory during treatment and therefore EEG investigations were performed every 4 hours.

EEG improved progressively to the point of almost normal after 48 hours in accordance to GCS score at 14 and in accordance to TCD in Middle Central Artery flow (before $52 \mathrm{~cm} / \mathrm{sec}$, after $80 \mathrm{~cm} / \mathrm{sec}$ ). Furthermore, cytokine levels decreased and hyperkinetic condition improved to normal kinetic condition.

In this study, MARS treatment increased systemic vascular resistance and arterial blood pressure and decreased CI and HR. As reported by Schimdt et al. [16] in some patients with acute liver failure, the ability to increase oxygen extraction is impaired, making $\mathrm{VO}_{2}$ directly dependent on CI.

This appeared to be the case in the present study, in which decreases in $\mathrm{CI}$ and $\mathrm{DO}_{2}$ were paralleled by a decrease in $\mathrm{VO}_{2}$. Of course, this might reflect a parallel reduction in systemic oxygen requirements, and no acidosis or increase in lactate levels to indicate anaerobic metabolism was observed after treatments.

After 48 hours MARS treatments and an evidence of clinical and biochemical improvement as previously published [17], we decided to stop emergency organ liver request.

The parameters conducive to a positive prognosis include: GCS $\geq 11, \mathrm{ICP}<15 \mathrm{~mm} \mathrm{Hg}$ or an improvement of the systolic peak flow of $25-32 \mathrm{~cm} / \mathrm{s}$ via Doppler ultrasound in the middle cerebral artery, lactate level $<3$ $\mathrm{mmol} / \mathrm{L}, \mathrm{TNF}-\alpha<20 \mathrm{pg} / \mathrm{mL}$, IL- $6<30 \mathrm{pg} / \mathrm{mL}$, and a change in hemodynamic instability from hyperkinetic to normal kinetic conditions.

We were therefore, able to continue treatment until complete clinical recovery of patient without resorting to liver transplantation. The patient survived and was discharged from the hospital in good condition after 40 days.

\section{REFERENCES}

[1] Lavanchy, D. (2009) The global burden of hepatitis C. Liver International, 29, 74-81. doi:10.1111/j.1478-3231.2008.01934.x

[2] Shepard, C.W., Finelli, L. and Alter, M.J. (2005) Global epidemiology of hepatitis C virus infection. Lancet Infectious Diseases, 5, 558-567. doi:10.1016/S1473-3099(05)70216-4

[3] Koulentaki, M., Ergazaki, M., Moschandrea, J., et al. 
(2001) Prevalence of hepatitis B and C markers in highrisk hospitalised patients in Crete: A five-year observational study. BMC Public Health, 1, 17. doi:10.1186/1471-2458-1-17

[4] Torresi, J., Johnson, D. and Wedemeyer, H. (2011) Progress in the development of preventive and therapeutic vaccines for hepatitis virus. Journal of Hepatology, 54, 1273-1285. doi:10.1016/j.jhep.2010.09.040

[5] Kubitschke, A., Bahr, M.J., Aslan, N., et al. (2007) Induction of hepatitis $\mathrm{C}$ virus (HCV)-specific $\mathrm{T}$ cells by needle stick injury in the absence of HCV-viraemia. European Journal of Clinical Investigation, 37, 54-64. doi:10.1111/j.1365-2362.2007.01753.x

[6] Deterding, K., Wiegand, J., Gruner, N., et al. (2008) Medical procedures as a risk factor for $\mathrm{HCV}$ infection in developed countries: Do we neglect a significant problem in medical care? Journal of Hepatology, 48, 1019-1020. doi:10.1016/j.jhep.2008.03.001

[7] Martinez-Bauer, E., Forns, X., Armelles, M., et al. (2008) Hospital admission is a relevant source of hepatitis $\mathrm{C}$ virus acquisition in Spain. Journal of Hepatology, 48, 2027. doi:10.1016/i.jhep.2007.07.031

[8] Esteban, J.I., Sauleda, S. and Quer, J. (2008) The changing epidemiology of hepatitis $\mathrm{C}$ virus infection in Europe. Journal of Hepatology, 48,148-162. doi:10.1016/j.jhep.2007.07.033

[9] Sen, S. and Williams, R. (2003) New liver support devices in acute liver failure: A critical evaluation. Seminars in Liver Disease, 23, 283-294. doi:10.1055/s-2003-42646

[10] Bernal, W., Auzinger, G., Dhawan, A. and Wendom, J. (2010) Acute liver failure. Lancet, 376, 190-191. doi:10.1016/S0140-6736(10)60274-7
[11] Sen, S., Williams, R. and Jalan, R. (2005) Emerging indications for albumin dialysis. American Journal of Gastroenterology, 100, 468-475. doi:10.1111/j.1572-0241.2005.40864.x

[12] Karvellas, K.J., Gibney, N., Kutsogiannis, D., Wendon, J., et al. (2007) Bench-to-bedside review: Current evidence for extracorporeal albumin dialysis systems in liver failure Critical Care, 11, 215. doi:10.1186/cc5922

[13] Trey, C. and Davidson, C.S. (1970) The management of fulminant hepatic failure. In: Popper, H. and Schaffner, F., Eds., Progress in Liver Diseases. New York: Grune and Stratton, 282-298.

[14] Isoniemi, H., Koivusalo, A.M., Repo, H., et al. (2005) The effect of albumin dialysis on cytokine levels in acute liver failure and need for liver transplantation. Transplantation Proceedings, 37, 1088-1090. doi:10.1016/j.transproceed.2004.11.060

[15] Riordan, S.M., Williams, R., et al. (2003) Mechanisms of hepatocyte injury, multiorgan failure, and prognostic criteria in acute liver failure. Seminars in Liver Disease, 23, 203-216. doi:10.1055/s-2003-42639

[16] Schmidt, L.E., Wang, L.P., et al. (2003) Systemic hemodynamic effects of treatment with the molecular adsorbents recirculating system in patients with hyperacute liver failure: A prospective controlled trial. Liver Transplantation, 9, 290-297. doi:10.1053/jlts.2003.50051

[17] Novelli, G., Morabito, V., Rossi, M., et al. (2009) Predictive Criteria for the Outcome of PatientsWith Acute Liver Failure Treated With the Albumin Dialysis Molecular Adsorbent Recirculating System. Therapeutic Apheresis and Dialysis, 13, 404-412. doi:10.1111/j.1744-9987.2009.00759.x 